CLINICAL STUDY

\title{
Skeletal muscle $11 \beta$ hydroxysteroid dehydrogenase type 1 activity is upregulated following elective abdominal surgery
}

\author{
Christina Jang $^{1,2}$, Varuni R Obeyesekere ${ }^{1}$, Frank P Alford ${ }^{1,2}$ and Warrick J Inder ${ }^{1,2}$ \\ ${ }^{1}$ Department of Endocrinology and Diabetes, St Vincent's Hospital, Melbourne, and ${ }^{2}$ Department of Medicine, University of Melbourne 41 Victoria Parade, \\ Fitzroy 3065, Australia
}

(Correspondence should be addressed to W J Inder; Email: winder@medstv.unimelb.edu.au)

\begin{abstract}
Objective: Cortisol has been traditionally implicated in the causation of peri-operative skeletal muscle (SkM) insulin resistance, but cortisol levels return to normal within $72 \mathrm{~h}$ of surgery. Tissue cortisol bioactivity may be prolonged by local upregulation of the enzyme 11ßHSD1. We aimed to investigate the changes of SkM 11ßHSD1 enzyme activity and mRNA expression, relative to plasma cortisol, insulin and glucose levels following elective abdominal surgery.

Patients and design: Eight non-diabetic subjects (two male, six female) underwent serial plasma hormone sampling and muscle biopsy of vastus lateralis at baseline and on day 5 following elective laparoscopic cholecystectomy.

Methods: SkM 11ßHSD1 and H6PDH mRNA levels were measured by quantitative RT-PCR and enzyme activity by $\%$ conversion of ${ }^{3} \mathrm{H}$ cortisone to cortisol. Plasma glucose, insulin, free fatty acids (FFA), tumour necrosis factor- $\alpha$ and cortisol by standardised assays.

Results: Compared with baseline, SkM 11ßHSD1 activity was significantly increased on day 5 after surgery $(14.7 \pm 2.1$ vs $20.4 \pm 3.2 \%, P=0.005)$. Neither $11 \beta$ HSD1 nor H6PDH mRNA levels were altered after surgery. Plasma cortisol $(P=0.027)$, FFA $(P=0.01)$ and glucose $(P=0.004)$ rose rapidly following surgery and had returned to baseline values by $24 \mathrm{~h}$ post-surgery. There was no significant change in plasma insulin.

Conclusions: This is the first study to demonstrate an upregulation of SkM 11ßHSD1 activity in response to a physiological stressor. Sustained activation of this enzyme may increase tissue cortisol bioactivity.
\end{abstract}

European Journal of Endocrinology $160249-255$

\section{Introduction}

The hypothalamic-pituitary-adrenal (HPA) axis constitutes a major part of the neuroendocrine system that controls the response to surgical stress (1). Both the HPA axis and sympathetic nervous system are activated by afferent nerve input from the area of surgical trauma (2). During elective abdominal surgery, circulating cortisol increases rapidly shortly after surgical incision, peaks at $6 \mathrm{~h}$ and remains elevated for up to $72 \mathrm{~h}$ postoperatively (3). No significant difference in the responses of cortisol or adrenaline has been observed between laparoscopic versus open cholecystectomy (4). Induction of anaesthesia does not appear to impact upon the plasma levels of ACTH, cortisol or the catecholamines (4).

Surgical trauma induces insulin resistance in normal and glucose intolerant individuals, which lasts postoperatively for at least one week (5). For example, following elective open cholecystectomy, insulin sensitivity is reduced maximally $(\sim 50 \%)$ on day 1 and by
30\% still by day 5 (5). Laparoscopic cholecystectomy is also associated with an increase in insulin resistance (6), albeit to a lesser extent than open surgery (7). Skeletal muscle is thought to be the main site of insulin resistance, and abnormalities of the insulin signalling cascade that have been demonstrated in the acute postoperative period (8). However, the causes or triggers for the development of this intracellular insulin resistance are unknown. Traditionally, the counter-regulatory hormones, particularly cortisol, but also glucagon, catecholamines and $\mathrm{GH}$ have been implicated in the pathogenesis of this insulin resistance.

Cytokines are also thought to be important mediators of insulin resistance (9). Both tumour necrosis factor- $\alpha$ (TNF $\alpha$ ) and interleukin-6 (IL-6) activate the HPA axis to stimulate ACTH and cortisol production (1). During abdominal surgery under general anaesthesia, cytokine levels increase gradually after skin incision and during surgery, peak on the first post-operative morning and return to baseline by the 7 th post-operative day. Following open cholecystectomy, both TNF $\alpha$ (10) and 
IL-6 levels increase, but laparoscopic surgery does not induce a cytokine response that is detectable in the systemic circulation (11).

$11 \beta$ hydroxysteroid dehydrogenase 1 (11ßHSD1) regulates local tissue exposure to active glucocorticoid (12). Oxoreductase activity of $11 \beta H S D 1$ is conferred by the endoplasmic reticulum enzyme hexose-6-phosphate dehydrogenase (H6PDH). We have recently demonstrated an increased activity of skeletal muscle (SkM) $11 \beta$ HSD1 in diabetic subjects following exogenous administration of the synthetic glucocorticoid dexamethasone, which induced a state of insulin resistant metabolic stress (13). There are no previous data describing whether SkM 11ßHSD1 expression or activity is altered at the time of a physiological stress. We postulated that an increase in SkM 11ßHSD1mediated generation of intracellular cortisol may occur in response to the physiological stress of surgery, which could prolong local cortisol bioactivity and an insulin resistant state at tissue level in the absence of a sustained plasma cortisol increase. In this study, we sought to examine in normal subjects the time course of plasma substrates (glucose and free fatty acids (FFA)), hormones (cortisol and insulin), cytokine (TNF $\alpha$ ) and SkM 11ßHSD1 enzyme activity and mRNA expression following elective cholecystectomy.

\section{Subjects and methods}

\section{Study subjects}

The study was approved by the St Vincent's Hospital Human Research Ethics Committee. Six women and two men undergoing elective laparoscopic cholecystectomy were recruited at pre-admission clinic. Seven of the patients had known cholelithiasis, while one woman had a thickened gall-bladder wall requiring removal. She was subsequently found to have an indolent lymphoma confined to the gall bladder and has not had any further specific treatment. Five of the subjects were on no medication, two were taking proton pump inhibitors, while one patient (a 33-year-old female) was on a maintenance dose of thyroxine for primary hypothyroidism and metformin $750 \mathrm{mg}$ twice daily for treatment of polycystic ovary syndrome. We had previously demonstrated that the use of metformin in subjects with type 2 diabetes did not alter SkM $11 \beta$ HSD1 activity compared with subjects on diet alone (13). During surgery, one subject required conversion to an open cholecystectomy because the gall bladder was adherent to omentum and colon. Surgery was uncomplicated for the remaining subjects. The mean age of the subjects was $51.5 \pm 5.1$ years; the mean body mass index (BMI) $35.5 \pm 2.7 \mathrm{~kg} / \mathrm{m}^{2}$ (range 25.0-47.6), and mean waist:hip ratio was $0.91 \pm 0.04$ (range 0.74-1.08). No subject was taking any medications known to affect the HPA axis. None of the subjects had significantly abnormal (twice upper limit of normal) liver function tests. Two subjects fulfilled criteria for the metabolic syndrome (14).

\section{Experimental design}

Biopsy of vastus lateralis muscle was performed using a $5 \mathrm{~mm}$ Bergstrom needle as previously described (15). Subjects underwent an initial muscle biopsy in the operation theatre after induction of anaesthesia and prior to the cholecystectomy. Surgery commenced in all subjects before $1000 \mathrm{~h}$. Subjects did not receive i.v. dextrose prior to surgery. The second biopsy was performed 4-6 days (median day 5) after the day of surgery on the contralateral vastus lateralis under sedation with i.v. midazolam and local anaesthetic after overnight fasting (15). No subject received any glucocorticoid or etomidate as part of their anaesthetic protocol. Fresh muscle (mean weight $192 \mathrm{mg}$, range $120-353 \mathrm{mg}$ ) was dissected free of visible adipose and connective tissue and placed immediately in serum-free DMEM (Invitrogen) for 11ßHSD1 activity studies (13). Separate samples were immediately snap frozen in liquid nitrogen (within $7 \mathrm{~s}$ ) for mRNA analysis and stored at $-70{ }^{\circ} \mathrm{C}$.

Blood sampling was performed on the following days in relation to the day of surgery (day 0 of protocol): days $-2,0,1,5$ and 28. Morning blood sampling was done after overnight fasting from $2200 \mathrm{~h}$. On the day of surgery, sampling was performed both prior to and $5 \mathrm{~h}$ after the commencement of surgery.

\section{Laboratory assays}

Plasma glucose was analysed by a glucose oxidase method employing YSI 1500 Sidekick analyser (Yellow Springs Instrument Company, Yellow Springs, OH, USA), coefficient of variation (CV) $2.4 \%$. Insulin was measured with an established RIA, with $<1 \%$ crossreactivity to proinsulin and sensitivity of $0.5 \mathrm{mU} / \mathrm{l}$ (16). Serum cortisol was measured with a competitive immunoassay using chemiluminescent technology (sensitivity $6 \mathrm{nmol} / \mathrm{l}$, intra-assay $\mathrm{CV}$ 6.3, 7.2 and $6.3 \%$ at concentrations 153, 492 and $782 \mathrm{nmol} / \mathrm{l}$ respectively, Bayer ADVIA Centaur). FFA were determined by an enzymatic colorimetric method using a kit (Wako Pure Chemical Industries, Osaka, Japan). TNF $\alpha$ was measured using a high sensitivity sandwich ELISA (sensitivity $0.12 \mathrm{pg} / \mathrm{ml}$, Quantikine, R\&D, Minneapolis, MN, USA). Homeostatic model assessment (HOMA-R) was calculated using the computer program of Levy et al. (17). The $\beta$-cell function index was calculated in the fasting basal steady state as follows: $20 \times($ fasting insulin $(\mu \mathrm{U} / \mathrm{ml}) /-$ fasting glucose (mmol/l))-3.5 (18). 


\section{Quantitative real time RT-PCR}

$11 \beta$ HSD1 and H6PDH mRNA expression in skeletal muscle were determined using quantitative real-time RT-PCR (Taqman Chemistry) as previously described (19). 11ßHSD1 specific primers and a probe were designed using Primer express 1.5 software (ABI, Foster City, CA, USA). Forward primer-5'-GCAAAGGGATCGGAAGAGAGA-3', reverse primer-5'-GCT GAGGCTGCTCCAAGCT-3', MGB FAM probe-5'-CCA CAT GGG CTC CCA-3'. For human H6PDH, a specific assayon-demand gene expression assay was obtained from Applied Biosystems (Foster City, CA, USA). Singleplex reactions were performed in triplicate and normalised to the endogenous control human 18s rRNA (Applied Biosystems). Data were obtained as $C_{\mathrm{t}}$ values, the cycle number at which logarithmic PCR plots cross a calculated threshold line, and expressed as $\Delta C_{t}$, the difference between $C_{\mathrm{t}}$ target and $C_{\mathrm{t}}$ endogenous control (mean $\Delta C_{t}$ values were obtained from two runs). Relative 11ßHSD1 mRNA levels and H6PDH levels were calculated using the $\Delta \Delta C_{\mathrm{t}}$ methodology $\left(\right.$ Formula $=2^{-\Delta \Delta C_{\mathrm{t}}}$ ). Total RNA from commercially obtained human skeletal muscle (BD Biosciences, Palo Alto, CA, USA) was reverse transcribed to cDNA and was used as the calibrator to obtain $\Delta \Delta C_{\mathrm{t}}$ values in all experiments.

\section{$11 \beta$ HSD1 activity}

Skeletal muscle $11 \beta$ HSD1 oxoreductase activity was quantified by the conversion of ${ }^{3} \mathrm{H}$ cortisone to cortisol as previously described (19). Within $4 \mathrm{~h}$ of the biopsy, fresh muscle was incubated in serum-free DMEM containing ${ }^{3} \mathrm{H}$ cortisone $(1 \mathrm{nM}$, specific activity $2.6 \mathrm{TBq} / \mathrm{mmol}), 100 \mathrm{nM}$ cold cortisone and $5 \mu \mathrm{g} / \mathrm{ml}$ insulin at $37^{\circ} \mathrm{C}$ with $5 \% \mathrm{CO}_{2}$ for $24 \mathrm{~h}$. Small clumps of muscle tissue were incubated to minimise disruption of cells. Steroids were then extracted with ethyl acetate, dried, resuspended in ethanol, and separated by thin layer chromatography (TLC) on plastic-backed silica gel 60 plates (Merck) using chloroform/ethanol (92:8) as solvent. The labelled cortisone and its converted product were visualised by phospho-imaging (Fujix BAS 1000; Fuji Film Company, Tokyo, Japan) and calculated as a percentage conversion (19).

\section{Statistical analysis}

SPSS v13.0 statistical software was used for statistical analysis (SPSS Inc., Chicago, IL, USA). Data are expressed as mean \pm s.E.M. Paired Students $t$-test was used to analyse 11ßHSD1 mRNA expression and enzyme activity data before and after surgery. One-way repeated measures ANOVA was used to assess differences in hormonal and biochemical parameters over the perioperative course. Pearson correlation analysis was employed to test the relationships between variables.
For one subject, a fasting blood sample was not obtained on the first post-operative day. Results for glucose, insulin and FFA were therefore imputed from the average of the other 7 patients' results at this time point.

\section{Results}

Demographic data of the subjects are shown in Table 1. At baseline, the surgical subjects had a high BMI, ranging from $25.0-47.6 \mathrm{~kg} / \mathrm{m}^{2}$ (Table 1 ). None of the surgical subjects were diabetic, but as expected, they had raised fasting insulin levels and were insulin resistant as measured by HOMA-R and QUICKI.

\section{Skeletal muscle $11 \beta H S D 1$ mRNA expression and enzyme activity at baseline}

$11 \beta$ HSD1 mRNA baseline levels and oxoreductase enzyme activity are shown in Table 1. As expected (19), the relative abundance of SkM H6PDH was 40 -fold higher compared with $11 \beta \mathrm{HSD} 1 \mathrm{mRNA}$ in skeletal muscle and this relationship did not change with surgery (data not shown).

\section{Skeletal muscle 11 $\beta$ HSD1 mRNA expression and enzyme activity after surgery}

$11 \beta$ HSD1 mRNA levels did not significantly change after surgery; mean $\Delta C_{\mathrm{t}} 19.60 \pm 0.52$ (before surgery) compared with $18.98 \pm 0.67$ (after surgery), $P=0.26$. The relative $11 \beta$ HSD 1 expression (compared with the commercial calibrator) before surgery was $3.27 \pm 0.99$ compared with 6.32 $2.23, P=0.133$ (Fig. 1a). H6PDH was also unchanged before and after surgery; mean $\Delta C_{\mathrm{t}} 14.50 \pm 0.52$ (before surgery) compared with $14.24 \pm 0.50$ (after surgery), $P=0.66$.

SkM 11ßHSD1 enzyme activity significantly increased after surgery: \% conversion ${ }^{3} \mathrm{H}$ cortisone to cortisol per $200 \mathrm{mg}$ muscle/24 h $14.7 \pm 2.1 \%$ before surgery compared with $20.4 \pm 3.2 \% 5$ days after surgery, $P=0.005$ (Fig. 1b). This increase of $11 \beta$ HSD1 activity occurred in all subjects, whereas an increase in 11ßHSD1 mRNA levels occurred in 5 out of

Table 1 Baseline data for surgical subjects.

\begin{tabular}{ll}
\hline$n(\mathrm{M} / \mathrm{F})$ & $2 / 6$ \\
Age (years) & $51.5 \pm 5.1$ \\
$\mathrm{BMl}\left(\mathrm{kg} / \mathrm{m}^{2}\right)$ & $35.5 \pm 2.7$ \\
WHR & $0.91 \pm 0.04$ \\
Glucose $(\mathrm{mmol} / \mathrm{l})$ & $4.9 \pm 0.27$ \\
Insulin $(\mu \mathrm{U} / \mathrm{ml})$ & $12.0 \pm 1.2$ \\
Cortisol $(\mathrm{nmol} / \mathrm{l})$ & $381 \pm 45$ \\
FFA (mmol/l) & $0.39 \pm 0.07$ \\
$11 \beta \mathrm{HSD} 1 \mathrm{activity}(\%$ conversion/200 mg/24 h) & $14.7 \pm 2.10$ \\
$11 \beta \mathrm{HSD} 1 \mathrm{mRNA}\left(\Delta C_{\mathrm{t}}\right)$ & $19.60 \pm 0.52$ \\
H6PDH mRNA $\left(\Delta C_{\mathrm{t}}\right)$ & $14.50 \pm 0.52$ \\
\end{tabular}



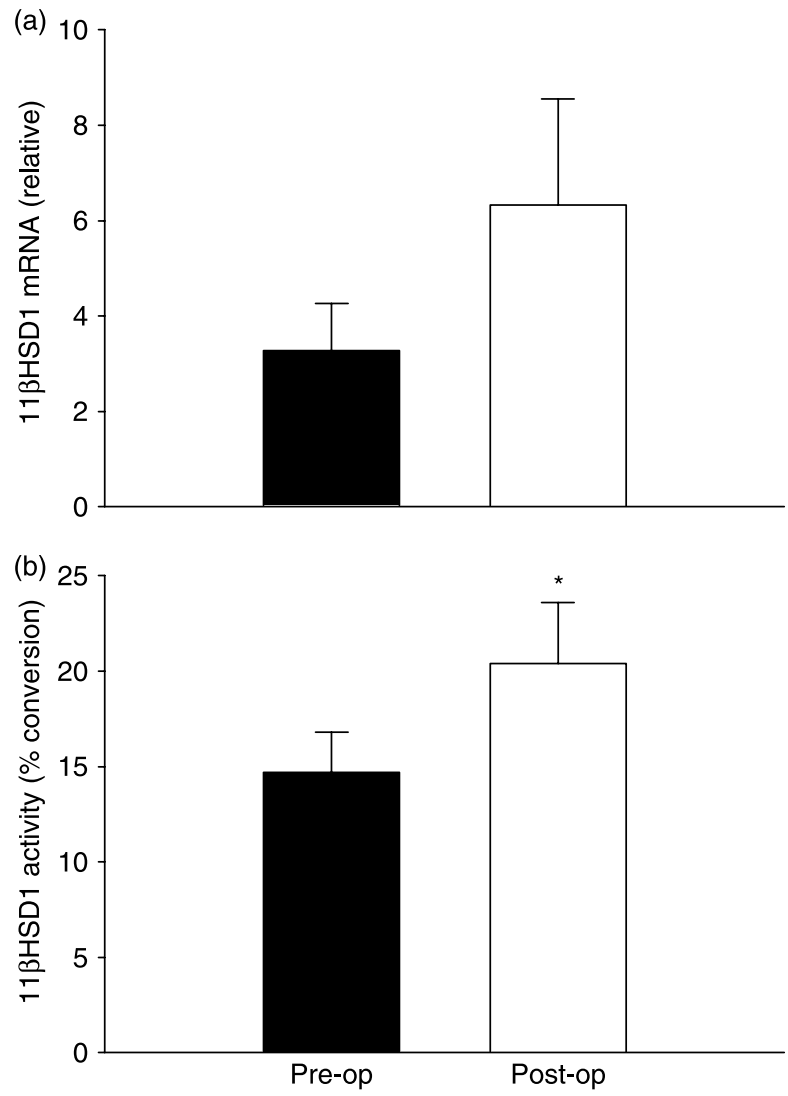

Figure $111 \beta \mathrm{HSD} 1$ relative mRNA levels and enzyme activity at baseline and $4-6$ days after surgery. ${ }^{*} P<0.05$ compared with before surgery.

8 subjects. There was no difference observed in $11 \beta$ HSD 1 mRNA or activity with respect to the timing of the post-operative biopsy (day 4,5 or 6 ).

\section{Biochemical data}

Cortisol changed significantly across the measured time points $(P=0.027)$, with a mean peak at $5 \mathrm{~h}$ postoperatively (Fig. 2a). However, this clearly defined peak was seen only in $50 \%$ of the subjects. The subjects who had no cortisol peak did not differ in age or BMI, but did have a higher HOMA-R $(P=0.045)$. There was no correlation between the change in SkM 11ßHSD1 activity and the change in cortisol from pre-operatively to their peak level $(r=-0.08, P=0.85)$.

Glucose and FFA also rose significantly (glucose $P=0.004$, FFA $P=0.01$ ), both peaking at $5 \mathrm{~h}$ postoperatively (Fig. $2 \mathrm{~b}$ and c). The $\beta$-cell function index fell significantly, with the nadir on the first post-operative day $(P=0.014$, Fig. $2 d)$. By contrast, there was no significant change in TNF $\alpha(P=0.09)$, insulin $(P=0.14)$, HOMA-R $(P=0.10)$ or QUICKI $(P=0.21)$ (Table 2).

There was no correlation between the change in $11 \beta$ HSD1 activity and the change in cortisol $(r=0.05$,
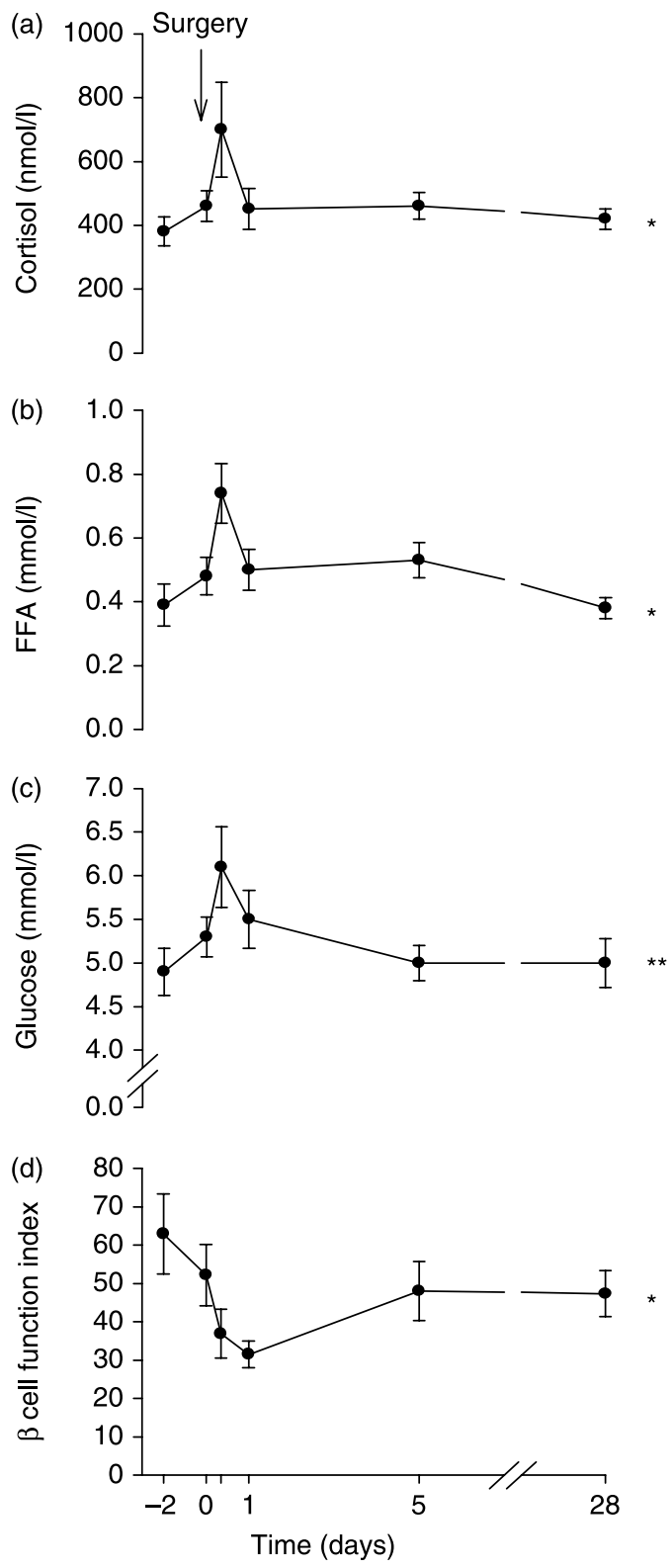

Figure 2 Mean levels of (a) cortisol, (b) FFA, (c) glucose and (d) $\beta$-cell function index during the perioperative time course. ${ }^{*} P<0.05$ and ${ }^{* *} P<0.01$ for a change across surgery by one-way repeated measures ANOVA for all parameters.

$P=0.90)$, glucose $(r=0.37, P=0.37)$ or change in FFA $(r=-0.46, P=0.25)$ from pre-operative to $5 \mathrm{~h}$ postoperatively.

\section{Discussion}

This study presents the novel finding that a physiological stressor, laparoscopic abdominal surgery, significantly stimulates $11 \beta$ HSD1 oxoreductase activity in skeletal muscle, despite no significant change in 
Table 2 Mean biochemical data at each time point.

\begin{tabular}{lcccccc}
\hline & Pre-op & Day 0 & Day 0+5 h & Day 1 & Day 5 & Day 28 \\
\hline Insulin $(\mu \mathrm{U} / \mathrm{ml})$ & $16.1 \pm 2.6$ & $14.9 \pm 2.4$ & $12.0 \pm 2.01$ & $9.5 \pm 1.25$ & $13.1 \pm 2.40$ & $13.1 \pm 2.11$ \\
HOMA-R & $2.1 \pm 0.32$ & $2.0 \pm 0.30$ & $1.6 \pm 0.27$ & $1.3 \pm 0.17$ & $1.7 \pm 0.31$ & $1.7 \pm 0.29$ \\
QUICKI & $0.32 \pm 0.009$ & $0.32 \pm 0.007$ & $0.33 \pm 0.008$ & $0.34 \pm 0.009$ & $0.33 \pm 0.007$ & $0.33 \pm 0.009$ \\
TNF $\alpha(\mathrm{pg} / \mathrm{ml})$ & $2.45 \pm 1.5$ & $2.52 \pm 1.79$ & $1.81 \pm 1.21$ & $1.80 \pm 0.96$ & $1.80 \pm 0.80$ & $2.63 \pm 1.7$ \\
\hline
\end{tabular}

11ßHSD1 mRNA content. The disparity between the significant increase in $11 \beta \mathrm{HSD} 1$ oxoreductase activity without a significant increase in mRNA expression is consistent with our previously published work (13). The change in enzyme activity was observed in all subjects, while five out of eight demonstrated a rise in mRNA expression. This highlights a lack of correlation between mRNA expression and enzyme activity which has been reported in other biological enzyme systems $(20,21)$. While given the small number of subjects studied, and the possibility that a type 2 error exists, important factors other than gene expression affect functional enzyme activity, including protein translation, posttranslational modification, protein-protein interactions and substrate availability. The study was statistically powered to show a difference in enzyme activity as the primary end point.

Post surgery, at a time when plasma cortisol had returned to basal levels, upregulation of SkM 11ßHSD1 activity may potentially increase local tissue levels of active cortisol in skeletal muscle. Using isotopically labelled cortisol, it is possible to examine 11ßHSD1 and 2 activity in vivo (22). This technique has been utilised to measure 11ßHSD1 and 2 activity in splanchnic and lower limb tissues (23). Such a measurement in our study would have been a valuable addition to the data, but is invasive, requiring femoral artery and vein cannulation in an angiography suite. In addition, we lacked the facilities to measure deuterium-labelled cortisol and cortisone. While further measures of SkM $11 \beta H S D 1$ oxoreductase activity across the post-operative period would have been desirable to map out a time course, it is difficult to justify ethically given the need for multiple invasive muscle biopsies. Day 5 was chosen because it was a time point where plasma cortisol would have been normal for several days. In an attempt to determine the mechanism of the observed SkM 11ßHSD1 activity upregulation, we have measured across the time of surgery, factors known to stimulate $11 \beta \mathrm{HSD} 1$ in other tissues.

The maximal mean cortisol response in this study was seen $5 \mathrm{~h}$ after the commencement of surgery. This is consistent with published literature that reports maximal cortisol levels occurred within $6 \mathrm{~h}$ of abdominal surgery $(1,24)$. However, in only half our subjects was there a clearly defined cortisol peak at this time point. Importantly, in the patients whose cortisol did not peak at $5 \mathrm{~h}$, an increase in SkM 11ßHSD1 oxoreductase activity was still consistently demonstrated. We found these subjects had a significantly higher HOMA-R as a marker of insulin resistance, but the relevance of this is unclear. One possible explanation for the lack of a cortisol peak at $5 \mathrm{~h}$ may be that the maximum perioperative cortisol for these subjects occurred prior to this time point. Donald et al. who compared the response of the entire HPA axis in subjects undergoing laparoscopic versus open cholecystectomy (4), reported that the maximal response in the laparoscopic subgroup was seen at $1 \mathrm{~h}$ post-operatively, which equates to $\sim 2 \mathrm{~h}$ after commencement of surgery (25). Therefore, there may still have been a significant increase in plasma cortisol above baseline in all subjects, which may have been identified by a more intensified blood sampling protocol.

Abdominal surgery has been associated with the development of insulin resistance (5-7). Although stress hormones have been implicated in the pathogenesis of this catabolic state, they return to normal within the first $72 \mathrm{~h}$ of surgery while the insulinresistance may persist for at least 5 days. Certainly, prolonged intracellular cortisol action may cause insulin resistance by inhibiting skeletal muscle GLUT4 translocation to the cell surface and reduce insulinstimulated glycogen synthesis (26). We hypothesised that there would be an increase in plasma insulin and HOMA-R across the time of surgery, but this proved not to be the case. One possible explanation for this is that the HOMA-R and QUICKI methods lacked the sensitivity to measure a change in insulin resistance in our small number of patients. Also, our surgical patients were already insulin resistant prior to surgery, which may have limited the extent of any further change in insulin resistance following surgery. Few data exist on the expected changes in fasting insulin, glucose and HOMA$\mathrm{R}$ in response to a surgical stress. In a study comparing the metabolic response to open versus laparoscopic cholecystectomy, Ortega et al. demonstrated a reduced insulin and glucose response 4 and $24 \mathrm{~h}$ postoperatively following the laparoscopic procedure (24). In Thorell's study which mapped out a peri-operative course of insulin resistance, the euglycaemic clamp was performed at several time points, including less than 5 days prior to surgery and post-operatively on days 1 , 5, 9 and 20 after surgery (5). Insulin resistance was maximal on the first post-operative day but still present on the 5th post-operative day being 30\% lower compared with the pre-operative values. In the decade since these studies were published, it is possible that 
refinements in laparoscopic surgical technique and anaesthesia may have further diminished the stress response, leading to less insulin resistance in the postoperative state.

Our data are more consistent with a reduction in $\beta$-cell function, as demonstrated by the significant fall in the $\beta$-cell index, rather than an increase in insulin resistance. A significant increase in plasma glucose was observed post-operatively while there was a nonsignificant trend for mean insulin levels to fall after surgery, with the lowest levels on the first post-operative day. A simultaneous reduction in insulin and rise in glucose, as seen in this study, have been previously demonstrated in response to direct sympathetic nerve stimulation (27). Adrenaline has been shown to directly inhibit the acute insulin response, and to stimulate hepatic glucose output (28). Therefore, the increased sympathetic drive seen during cholecystectomy $(4,24)$ may account for the alterations of glucose and insulin in this study. These observations suggest that while insulin resistance is one possible mechanism underlying the metabolic perturbations associated with abdominal surgery, relative insulin deficiency may also be an important factor. This may be particularly relevant in the presence of co-existing insulin resistance in this patient group. Although, insulin is a stimulus to adipose tissue 11ßHSD1 (29), the observed time course of plasma insulin levels do not account for the increased $11 \beta$ HSD1 activity in skeletal muscle.

A rise in the level of circulating FFA occurred around the time of surgery, with peak levels at $5 \mathrm{~h}$ after the commencement of surgery. There are limited data examining the changes in FFA specifically during laparoscopic cholecystectomy. One study comparing the lipid responses of patients undergoing laparoscopic compared with open cholecystectomy found a significant rise in FFA in both groups post-operatively (30), while another found that FFA fell significantly with surgery (31). However, glucocorticoids and increased sympathetic tone are known to induce lipolysis (32) which could account for the increase in FFA. While a direct effect of elevated FFA on skeletal muscle 11ßHSD1 has not to our knowledge been examined, the possibility arises that the FFA elevation noted in the current study could in part cause the upregulation of 11ßHSD1 activity, given that it has been noted that intralipid infusion upregulated 11ßHSD1 mRNA in adipose tissue (29). While we acknowledge that the peak in FFA occurred in the early post-operative period, it cannot be excluded that a short lived increase in a stimulatory factor might have a longer term effect on SkM 11ßHSD1 activity.

The role of inflammatory cytokines in the stress response to the surgical procedure was examined because TNF $\alpha$ has been shown to increase 11ßHSD1 activity in primary cultures of adipose stromal cells in vitro (33). Cytokine production in adipocytes may stimulate 11ßHSD1-mediated cortisol generation within adipose tissue that then promotes adipocyte differentiation (34). TNF $\alpha$ also upregulates 11ßHSD1 in glomerular mesangial cells (35). Our study found no significant increase in plasma TNF $\alpha$ across the period of surgery, but this does not exclude a local tissue effect on SkM 11ßHSD1 oxoreductase activity. This lack of a significant change in plasma TNF $\alpha$ is consistent with previous reports comparing laparoscopic and open cholecystectomy $(11,36)$.

In conclusion, this study has demonstrated a significant upregulation of skeletal muscle 11ßHSD1 oxoreductase activity in subjects undergoing elective laparoscopic cholecystectomy when assessed at day 5 post-operatively, when plasma cortisol had returned to baseline. This increase was not associated with consistent changes in any of the factors known to upregulate $11 \beta \mathrm{HSD} 1$ in other tissues. This is the first study to report an acute physiological stressor increasing activity of 11ßHSD1 in human tissue.

\section{Declaration of interest}

C Jang has received lecture fees from Novo Nordisk. W J Inder has received lecture fees from Novartis, Novo Nordisk and Eli Lilly. V R Obeyesekere and F P Alford have nothing to disclose.

\section{Funding}

This study was supported by grants from the National Health and Medical Research Council of Australia, St Vincent's Hospital Melbourne, and GlaxoSmithKline Research Grant.

\section{Acknowledgements}

We thank Associate Professor Stephen Farish for his statistical advice and the Department of Hepatobiliary Surgery at St Vincent's Hospital, Melbourne for their cooperation throughout this study.

\section{References}

1 Naito Y, Tamai S, Shingu K, Shindo K, Matsui T, Segawa H, Nakai Y \& Mori K. Responses of plasma adrenocorticotropic hormone, cortisol, and cytokines during and after upper abdominal surgery. Anesthesiology 199277 426-431.

2 Udelsman R, Norton JA, Jelenich SE, Goldstein DS, Linehan WM, Loriaux DL \& Chrousos GP. Responses of the hypothalamicpituitary-adrenal and renin-angiotensin axes and the sympathetic system during controlled surgical and anesthetic stress. Journal of Clinical Endocrinology and Metabolism 1987 64 986-994.

3 Naito Y, Fukata J, Tamai S, Seo N, Nakai Y, Mori K \& Imura H. Biphasic changes in hypothalamo-pituitary-adrenal function during the early recovery period after major abdominal surgery. Journal of Clinical Endocrinology and Metabolism 199173 111-117.

4 Donald RA, Perry EG, Wittert GA, Chapman M, Livesey JH, Ellis MJ, Evans MJ, Yandle T \& Espiner EA. The plasma ACTH, AVP, CRH and catecholamine responses to conventional and laparoscopic cholecystectomy. Clinical Endocrinology 199338 609-615.

5 Thorell A, Efendic S, Gutniak M, Haggmark T \& Ljungqvist O. Insulin resistance after abdominal surgery. British Journal of Surgery 199481 59-63.

6 Hawthorne GC, Ashworth L \& Alberti KG. The effect of laparoscopic cholecystectomy on insulin sensitivity. Hormone and Metabolic Research 199426 474-477. 
7 Thorell A, Nygren J, Essen P, Gutniak M, Loftenius A, Andersson B \& Ljungqvist $O$. The metabolic response to cholecystectomy: insulin resistance after open compared with laparoscopic operation. European Journal of Surgery 1996162 187-191.

8 Thorell A, Nygren J, Hirshman MF, Hayashi T, Nair KS, Horton ES, Goodyear LJ \& Ljungqvist O. Surgery-induced insulin resistance in human patients: relation to glucose transport and utilization. American Journal of Physiology 1999276 E754-E761.

9 Ljungqvist O, Nygren J \& Thorell A. Insulin resistance and elective surgery. Surgery $2000 \mathbf{1 2 8} 757-760$.

10 Chaudhary D, Verma GR, Gupta R, Bose SM \& Ganguly NK. Comparative evaluation of the inflammatory mediators in patients undergoing laparoscopic versus conventional cholecystectomy. Australian and New Zealand Journal of Surgery 199969 369-372.

11 Kristiansson M, Saraste L, Soop M, Sundqvist KG \& Thorne A. Diminished interleukin-6 and C-reactive protein responses to laparoscopic versus open cholecystectomy. Acta Anaesthesiologica Scandinavica $1999 \mathbf{4 3} 146-152$.

12 Stewart PM \& Whorwood CB. 11ß-Hydroxysteroid dehydrogenase activity and corticosteroid hormone action. Steroids $1994 \mathbf{5 9}$ 90-95.

13 Jang C, Obeyesekere VR, Dilley RJ, Krozowski Z, Inder WJ \& Alford FP. Altered activity of $11 \beta$-hydroxysteroid dehydrogenase types 1 and 2 in skeletal muscle confers metabolic protection in subjects with type 2 diabetes. Journal of Clinical Endocrinology and Metabolism 200792 3314-3320.

14 Alberti KG, Zimmet P \& Shaw J. The metabolic syndrome - a new worldwide definition. Lancet 2005366 1059-1062.

15 Christopher M, Hew FL, Oakley M, Rantzau C \& Alford F. Defects of insulin action and skeletal muscle glucose metabolism in growth hormone-deficient adults persist after 24 months of recombinant human growth hormone therapy. Journal of Clinical Endocrinology and Metabolism $1998 \mathbf{8 3} 1668-1681$.

16 Mclachlan KA \& Alford FP. The impact of acute elevation of nonesterified fatty acids on insulin sensitivity and secretion in women with former gestational diabetes. Clinical Endocrinology 200562 79-84.

17 Levy JC, Matthews DR \& Hermans MP. Correct homeostasis model assessment (HOMA) evaluation uses the computer program. Diabetes Care 199821 2191-2192.

18 Eisenhardt S, Schwarzmann N, Henschel V, Germeyer A, Von Wolff M, Hamann A \& Strowitzki T. Early effects of metformin in women with polycystic ovary syndrome: a prospective randomized, double-blind, placebo-controlled trial. Journal of Clinical Endocrinology and Metabolism 200691 946-952.

19 Jang C, Obeyesekere VR, Dilley RJ, Alford FP \& Inder WJ. 11ß hydroxysteroid dehydrogenase type 1 is expressed and is biologically active in human skeletal muscle. Clinical Endocrinology $2006 \mathbf{6 5} 800-805$.

20 Glanemann C, Loos A, Gorret N, Willis LB, O’Brien XM, Lessard PA \& Sinskey AJ. Disparity between changes in mRNA abundance and enzyme activity in Corynebacterium glutamicum: implications for DNA microarray analysis. Applied Microbiology and Biotechnology 200361 61-68.

21 Pachucki J, Ambroziak M, Tanski Z, Luczak J, Nauman J \& Nauman A. Type I 5'-iodothyronine deiodinase activity and mRNA are remarkably reduced in renal clear cell carcinoma. Journal of Endocrinological Investigation 2001 24 253-261.

22 Andrew R, Smith K, Jones GC \& Walker BR. Distinguishing the activities of 11ß-hydroxysteroid dehydrogenases in vivo using isotopically labeled cortisol. Journal of Clinical Endocrinology and Metabolism 200287 277-285.
23 Basu R, Singh RJ, Basu A, Chittilapilly EG, Johnson CM, Toffolo G, Cobelli C \& Rizza RA. Splanchnic cortisol production occurs in humans: evidence for conversion of cortisone to cortisol via the 11-beta hydroxysteroid dehydrogenase type 1 pathway. Diabetes $2004532051-2059$.

24 Ortega AE, Peters JH, Incarbone R, Estrada L, Ehsan A, Kwan Y, Spencer CJ, Moore-Jeffries E, Kuchta K \& Nicoloff JT. A prospective randomized comparison of the metabolic and stress hormonal responses of laparoscopic and open cholecystectomy. Journal of the American College of Surgeons 1996183 249-256.

25 Majeed AW, Troy G, Nicholl JP, Smythe A, Reed MW, Stoddard CJ, Peacock J \& Johnson AG. Randomised, prospective, single-blind comparison of laparoscopic versus small-incision cholecystectomy. Lancet 1996347 989-994.

26 Ruzzin J, Wagman AS \& Jensen J. Glucocorticoid-induced insulin resistance in skeletal muscles: defects in insulin signalling and the effects of a selective glycogen synthase kinase-3 inhibitor. Diabetologia 200548 2119-2130.

27 Bloom SR, Edwards AV \& Jones CT. Neuroendocrine responses to stimulation of the splanchnic nerves in bursts in conscious, adrenalectomized, weaned lambs. Journal of Physiology 1989417 79-89.

28 Martin IK, Weber KM, Boston RC, Alford FP \& Best JD. Effects of epinephrine infusion on determinants of intravenous glucose tolerance in dogs. American Journal of Physiology 1988255 E668-E673.

29 Wake DJ, Homer NZ, Andrew R \& Walker BR. Acute in vivo regulation of 11 beta-hydroxysteroid dehydrogenase type 1 activity by insulin and intralipid infusions in humans. Journal of Clinical Endocrinology and Metabolism $2006914682-4688$.

30 Saranteas T, Voukena V, Zotos N, Stranomiti J, Kondadaki A, Tachmintzi A, Pantos C, Tesseromatis C \& Dimitriou V. Lipid kinetics in obese patients undergoing laparoscopy. The impact of cortisol inhibition by etomidate. European Journal of Drug Metabolism and Pharmacokinetics 200429 187-192.

31 Targarona EM, Pons MJ, Balague C, Espert JJ, Moral A, Martinez J, Gaya J, Filella X, Rivera F, Ballesta A \& Trias M. Acute phase is the only significantly reduced component of the injury response after laparoscopic cholecystectomy. World Journal of Surgery 199620 528-533.

32 Leung K \& Munck A. Peripheral actions of glucocorticoids. Annual Review of Physiology 197537 245-272.

33 Tomlinson JW, Moore J, Cooper MS, Bujalska I, Shahmanesh M, Burt C, Strain A, Hewison M \& Stewart PM. Regulation of expression of 11beta-hydroxysteroid dehydrogenase type 1 in adipose tissue: tissue-specific induction by cytokines. Endocrinology $20011421982-1989$.

34 Bujalska IJ, Kumar S, Hewison M \& Stewart PM. Differentiation of adipose stromal cells: the roles of glucocorticoids and 11 betahydroxysteroid dehydrogenase. Endocrinology $1999 \mathbf{1 4 0}$ 3188-3196.

35 Escher G, Galli I, Vishwanath BS, Frey BM \& Frey FJ. Tumor necrosis factor alpha and interleukin 1beta enhance the cortisone/cortisol shuttle. Journal of Experimental Medicine 1997 186 189-198.

36 Helmy SA, Wahby MA \& El-Nawaway M. The effect of anaesthesia and surgery on plasma cytokine production. Anaesthesia $1999 \mathbf{5 4}$ $733-738$.

Received 14 October 2008

Accepted 8 November 2008 